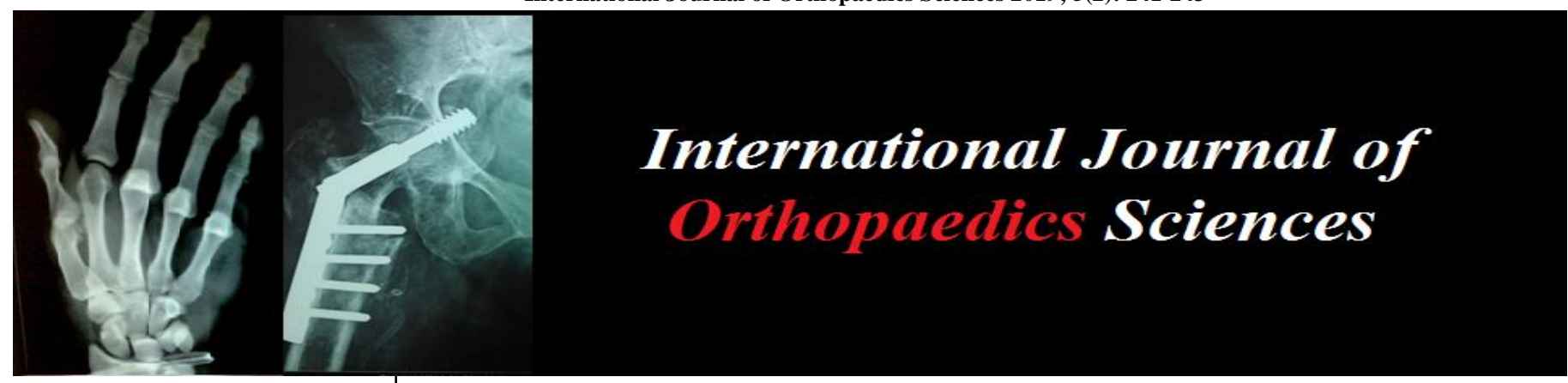

ISSN: $2395-1958$

IJOS 2019; 5(2): 241-243

(C) 2019 IJOS

www.orthopaper.com

Received: 11-02-2018

Accepted: 13-03-2018

Dr. Varun Goel

Department of Orthopedics,

Pt.BD. Sharma PGIMS, Rohtak,

Haryana, India

Dr. Neha Bhardwaj

Adesh Institute of Medical

Sciences, Bhatinda, Punjab,

India

Dr. Jay Dhariwal

Department of Orthopedics, Pt.

BD. Sharma PGIMS, Rohtak,

Haryana, India

Dr. Surinder Jaiswal

Department of Orthopaedics, Pt. BD. Sharma PGIMS, Rohtak,

Haryana, India

Dr. Darshan MS

Department of Orthopaedics, $\mathrm{Pt}$. BD. Sharma PGIMS, Rohtak,

Haryana, India

\section{Vascularized bone graft in Herbert type D scaphoid fractures}

\author{
Dr. Varun Goel, Dr. Neha Bhardwaj, Dr. Jay Dhariwal, Dr. Surinder \\ Jaiswal and Dr. Darshan MS
}

DOI: https://doi.org/10.22271/ortho.2019.v5.i2e.28

\section{Abstract}

Introduction: Scaphoid fractures are very notorious to unite. These fractures are usually undiagnosed or overlooked, thus presenting late as non-union. Non-Union Scaphoid is a common complication of Scaphoid fracture which is quite challenging to treat. Casts or Closed reductions or even open reduction with simple bone grafts are generally not enough, so we did pronator quadratus osteomuscular transposition flap to revascularise the non-union Scaphoid. A series of 7 cases treated using vascularized bone graft.

Material and Methods: This study was done on seven cases of non-union Scaphoid with Pronator Quadratus vascularized bone graft. Alnot classification and Herbert classification was use. Postoperatively cases were assessed clinically and radiologically.

Results: Six out of total 7 cases had satisfactory clinical outcome and 1 case complained of restricted and painful wrist movements.

Conclusion: Vascularized bone grafts have excellent results in otherwise difficult to treat non union Scaphoid.

Keywords: Nonunion scaphoid, pronator quadratus, vascularized bone graft

\section{Introduction}

Scaphoid is the most common carpal to get fractured and also the most notorious one to go into non-union and avascular necrosis (AVN) which inevitably causes wrist arthritis. Scaphoid has a vulnerable blood supply ${ }^{[1,2]}$; majority of blood supply is from distal to proximal which gets hampered by the fracture. Scaphoid has a thin waist, oblique alignment and its multiplanar motion. The compressive forces tend to collapse and angulate the Scaphoid fracture fragments, leading to extension of proximal pole and flexion collapse of the distal pole. All of these makes if more prone to fracture and difficult to unite.

Majority of the fractures of Scaphoid are through proximal pole $(95.6 \%)$ and of these $63 \%$ are displaced fractures ${ }^{[3]}$ Proximal pole fractures has higher chances of landing into non-union and ultimately AVN ${ }^{[4,5]}$. Scaphoid is supplied by dorsal and palmer branches of Radial artery. The dorsal vessels enter through non-articular surface of distal half and palmer vessels enter through the tubercle. Dorsal vessels nourish the proximal $2 / 3^{\text {rd }}$ of the Scaphoid. Scaphoid is vascularized $80 \%$ by its dorsal vessels and $20 \%$ by palmar vessels ${ }^{[6]}$.

Earlier below elbow glass holding Scaphoid casts remained the mainstay treatment of all types of Scaphoid fractures, may it be of proximal or distal pole, displaced or undisplaced. Later with advanced scoring system and techniques and longer follow up showed it to have failure rates as high as $65 \%{ }^{[7]}$. Then free cancellous bone graft came into picture, which also had certain limitations and thus gradually became less preferred option. Vascularized bone grafts gained greatest popularity as it was a more biological solution since it preserved viability of osteoblasts and osteoclasts.

\section{Materials and Methods}

Study was done in 2013-2018 over 7 cases of non-union Scaphoid with patient's informed consent. Among the patients all 7 were men and majority of the patients were farmer and labour.
Dr. Varun Goel

Department of Orthopedics, Pt.BD. Sharma PGIMS, Rohtak,

Haryana, India 
Their mean age was 32 years (ranging from 20 to 47 years) and $66.67 \%$ fractures were of right hand and $33.33 \%$ of left hand. Mean time period between injury and surgical intervention was 8 months (ranging from 6 months -2 years) Herbert classification was used to classify Scaphoid fractures [Table 1]. All cases were cases of established non-union with either fibrous non-union or pseudoarthrosis, i.e. Herbert type D. According to Alnot classification ${ }^{[8]}$, all the 7 cases were of type $2 \mathrm{a}$ and $2 \mathrm{~b}$. None of the patients had radio scaphoid or radiocarpal arthritis or proximal pole necrosis.

The technique was given by Kuhlmann et al. ${ }^{[9]}$. Seromuscular graft was taken from anteromedial cortex of distal radius on a pedicle of lower fibers of pronator quadratus muscle. This muscle pedicle had a volar carpal branch of anterior interosseous artery which nourishes the graft.
Brachial block was given in all the patients and a digital pneumatic tourniquet applied over the arm. A classic anterior incision was given and Scaphoid exposed. Non-union area of both proximal and distal fragments prepared. The incision was then extended proximally to expose the donor site. Graft harvested from anteromedial cortex of radius with intact inferior fibers of pronator quadratus and its supplying artery. Pronator quadratus was freed from its origin to make the osteomuscular flap mobile. The tourniquet was then deflated to confirm graft vascularity. The graft is then put into the Scaphoid bony defect without putting strain on pedicle and fixed with a k-wire from distal to proximal fashion. Wound closed in layers and below elbows slab applied in neutral position. After 14 days sutures removed and short arm cast applied for 6 weeks. After which k-wire removed and physiotherapy started.

Table 1: Herbert classification of Scaphoid fractures

\begin{tabular}{|c|c|}
\hline A - Stable acute fractures & A1 - Fracture of tubercle \\
\hline & A2 - Incomplete fracture through the waist \\
\hline B-Unstable acute fractures & B1 - Distal oblique fracture \\
\hline & B2-Complete fracture of waist \\
\hline & B3-Proximal pole fracture \\
\hline C-Delayed Union & B4-Trans-Scaphoid perilunate fracture dislocation of carpus \\
\hline D-Established non-union & D1 - Fibrous union \\
\hline & D2 - Pseudoarthrosis \\
\hline
\end{tabular}

\section{Result}

Utmost care was taken intraoperative not to damage or fracture muscle pedicle or its vessel. None of the cases had postoperative complications like infection or k-wire migration. Mean follow up period was 2.1 years (8 months 4 years).

The assessment of clinical outcome was done under following points as Range of Movement of wrist, strength and pain relief. Post op x-rays were done to analyse radiological bone union.

6 out of total 7 cases had satisfactory clinical outcome but 1 case complained of restricted and painful wrist movements. 6 out of 7 cases showed good bone union radiologically. None of the cases showed any signs of Scaphoid necrosis. Revision surgery was not done in any of the cases.

\section{Discussion}

Fractures of Scaphoid are quite common and are very easily missed if not evaluated properly. Management of these fractures are also challenging as the failure rate with conventional Scaphoid cast varies from 5-10\% [10]. Failed cases landing into non-union usually require specialized surgical procedures like bone grafting to unite. Bone grafting can be conventional bone graft or vascularized bone graft.
Union rate of various bone grafts varies widely, it yields 7092\% success rates ${ }^{[11-16]}$. Conventional free bone grafts and vascularized bone grafts have been compared in Table 2. In our study $85.71 \%$ patients had satisfactory outcome clinically and radiologically.

Vascularized pronator quadratus osteomuscular transposition flap from the anteromedial radius is a very high yielding and reliable surgical option for non-union fracture Scaphoid but harvesting such small graft with intact muscle pedicle and its nourishing vessel is a very meticulous and tactful technique. Another challenge was mobility of the graft and pedicle to the non-union site. This requires experienced hands in order to achieve high success rates. In all the study cases k-wires were used to fix the graft. None of cases Herbert screws were used as it was difficult to insert and it displaced the small graft. Instead k-wires were easy to insert and it didn't displace the graft. The drawback of k-wires was that there was slight chance of graft displacement as the fixation was not very rigid.

Post-operatively mild-moderate pain is a very common and consistent problem. Studies have shown as high as $100 \%{ }^{[12]}$ patients had pain post-operative pain. Smoking and increased age has also been shown to affect bone union ${ }^{[17]}$.

Table 2: Comparison of different bone grafting techniques

\begin{tabular}{|c|c|c|}
\hline Author & Technique and type of Graft & Bone Union Rate \\
\hline Chantelot $^{[11]}$ & Matti-Russe Free cancellous bone graft & $81 \%$ \\
\hline Sameul Ribok $^{[12]}$ & Non-Vascularised graft & $72.5 \%$ \\
\hline & Vascularised graft & $89.1 \%$ \\
\hline Chang $^{[13]}$ & Zaidemberg & $71 \%$ \\
\hline Mohd faouzi $^{[14]}$ & Kuhlmann Vascularised radial bone graft $^{15}$ & $88.5 \%$ \\
\hline Mathoulin $^{[15]}$ & Kuhlmann & $92 \%$ \\
\hline Guimberteau $^{[16]}$ & Ulnar bone graft nourished by ulnar artery \\
\hline
\end{tabular}




\section{Conclusion}

Conservative management is not always very rewarding and fractures of Scaphoid land into non-union. Non unions Scaphoid are still more difficult to treat. There are a number of available surgical options but excellent results with vascularized pedicle graft have changed the protocol for nonunion scaphoid completely and made the older technique obsolete.

\section{References}

1. Gelberman RH, Gross MS. The vascularity of the wrist. Identification of arterial patterns at risk. Clin Orthop Relat Res. 1986; 202:40-9.

2 Gelberman RH, Menon J. The vascularity of the Scaphoid bone. J Hand Surg Am. 1980; 5:508-13.

3 Chari PR. Fresh fractures of the Scaphoid: A rationale method of treatment. Indian Journal of Orthopaedics. 2006; 40:250-4.

4 Herbert TJ, Fisher WE. Management of the fractured Scaphoid using a new bone screw. J Bone Joint Surg Br. 1984; 66:114-23.

5 Cooney WP, Dobyns JH, Linscheid RL. Non-union of the Scaphoid: analysis of the results from bone grafting. J Hand Surg [Am]. 1980; 5:343-54.

6 Khanojiya RK, Gaur SC, Asthana AK. Avascular necrosis of Scaphoid: a comparative study. Indian Journal of orthopaedics. 1999; 33:175-7.

7 Gelberman RH, Menon J. The vascularity of Scaphoid bone. J Hand Surg Am. 1980; 5:508-18.

8 Alnot JY. Fractures et pseudarthroses du scaphoïde carpien. - Revue de chirurgie orthopédique, 1988; 74:714-717

9 Kuhlman JN, Mimoun M, Boabighi A, Baux S. Vascularized bone graft pedicled on the volar carpal artery for nonunion of the Scaphoid. - Journal of hand surgery. 1987, 12:203-210.

10 Rajagopalan BM, Squire DS, Samuels LO. Results of Herbert-screw fixation with bone-grafting for the treatment of non-union of the Scaphoid. J Bone Joint Surg Am 1999; 81:48-52.

11 Chantelot C, Frebault C, Limousin M, Robert G, Migaud $\mathrm{H}$, Fontaine C. Long-term outcome of non-vascularized grafts for carpal Scaphoid nonunion. Rev Chir Orthop Reparatrice Appar Mot 2005; 91:724-31.

12 Ribak S, Medina CEG, Mattar R, Ulson HJR, Resende MR, Etchebehere M. Treatment of Scaphoid non-union with vascularised and nonvascularised dorsal bone grafting from distal radius. Int Orthop. 2010; 34:683-8.

13 Chang MA, Bishop AT, Moran SL, Shin AY. The outcomes and complications of 1, 2-intercompartmental supraretinacular artery pedicled vascularized bone grafting of Scaphoid nonunions. J Hand Surg Am. 2006; 31:387-96.

14 Hamdi MF, Amare K, Tarhouni L, Baccari S. Non union scaphoid treated by anterior vascularised bone graft: A review of 26 cases. Chin J Traumatol. 2011; 14:205-8.

15 Mathoulin C, Haerle M. Vascularized bone graft from the palmar carpal artery for treatment of Scaphoid nonunion. J Hand Surg Br 1998; 23(3):318-23.

16 Guimberteau JC, Panconi B. Recalcitrant nonunion of the scaphoid treated with a vascularized bone graft based on the ulnar artery - Journal of bone and joint surgery 1990; 72A:88-97.

17 Little CP, Burston BJ, Hopkinson-Woolley J, Burge P. Failure of surgery for scaphoid non -union is associated with smoking. J Bone Joint Surg [Br]. 2006; 31:252-255. 